SFB

Ordinal pattern dependence between hydrological time series

823

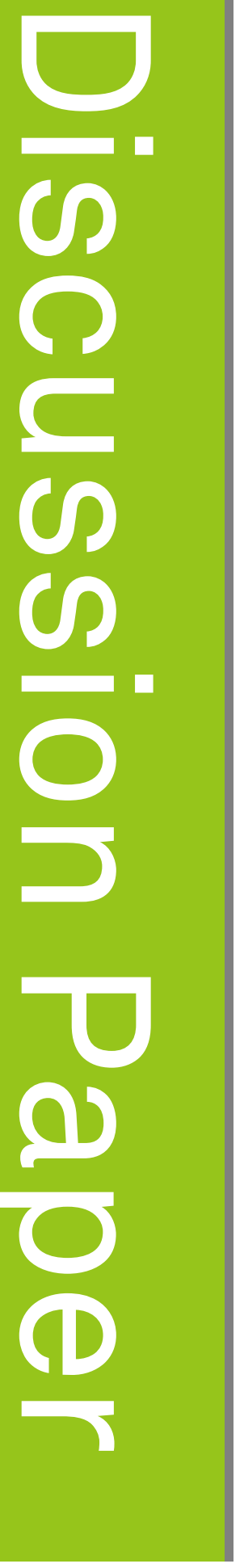

Svenja Fischer, Andreas Schumann, Alexander Schnurr

Nr. 88/2016

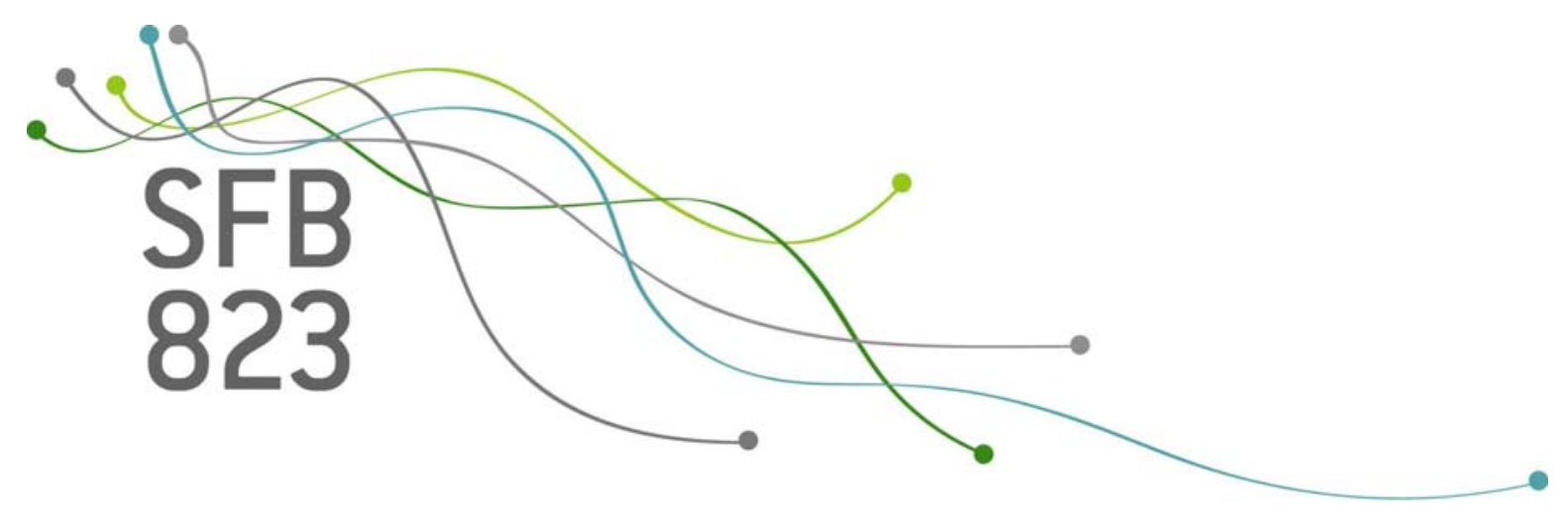





\title{
Ordinal Pattern Dependence between hydrological time series
}

\author{
Svenja Fischer * Andreas Schumann ${ }^{\dagger} \quad$ Alexander Schnurr ${ }^{\ddagger}$
}

\begin{abstract}
Ordinal patterns provide a method to measure correlation between time series. In contrast to classical correlation measures like the Pearson correlation coefficient they are able to measure not only linear correlation but also non-linear correlation even in the presence of non-stationarity. Hence, they are a noteworthy alternative to the classical approaches when considering discharge series. Discharge series naturally show a high variation as well as single extraordinary extreme events and, caused by anthropogenic and climatic impacts, non-stationary behaviour. Here, the method of ordinal patterns is used to compare pairwise discharge series derived from macroand mesoscale catchments in Germany. Differences of coincident groups were detected for winter and summer annual maxima. Hydrological series, which are mainly driven by annual climatic conditions (yearly discharges and low water discharges) showed other and in some cases surprising interdependencies between macroscale catchments. Anthropogenic impacts as the construction of a reservoir or different flood conditions caused by urbanization could be detected.
\end{abstract}

KEYWORDS: ordinal patterns; discharge correlation; homogeneous groups MSC[2010] 62-07; 91G70; 91B84; 62M10

\section{Introduction}

Hydrological catchments are the basic spatial units considered in hydrology. They are conceptualized as complex dynamical systems where deterministic and stochastic processes occur simultaneously. It is recognized that there is a strong need for the classification of catchments and hydrological phenomena ([4) in the framework of comparative hydrology. The similarity of discharge regimes is a fundamental criterion for regionalisation. For this purpose, time series of characteristic runoff values (averages, upper and lower extremes), which are derived from discharge series have to be compared to analyse the impacts of spatial heterogeneous distributed climate characteristics as well as of differences of hydrological processes at the catchment scale. The spatial covariance (correlation) is often applied as a measure of the interrelationship between time series. It is the statistical basic tool for interpolation and consistent mapping of runoff and its statistical descriptors. One problem of this approach consists in the non-linearity of runoff processes. To give an example: an urbanized catchment will react more directly on a flood inducing rainfall than a natural one. If we consider two rain events, which differ in

\footnotetext{
*svenja.fischer@rub.de, Institute of Hydrology, Ruhr-University Bochum, Germany

${ }^{\dagger}$ andreas.schumann@rub.de, Institute of Hydrology, Ruhr-University Bochum, Germany

${ }^{\ddagger}$ schnurr@mathematik.uni-siegen.de, Department of Mathematics, Universitt Siegen, Germany
} 


\section{Methodology}

size, the urbanized catchment will produce more runoff from the higher amount of rainfall in relationship to the natural catchment. If we compare the runoff data from both catchments we see the same tendencies (one event is higher than the other), but the quantitative relationships between both events differ between the two catchments. As a result, a linear regression model would not be appropriated to describe the statistical relationship between the two runoff series. Ordinal patterns ([2]) are a simple approach to characterize the synchronicity of time series without quantification of the variances of the time series, which are affected by non-linearities or scale effects and not comparable in many cases. Ordinal patterns were applied in hydrology for time series analyses, e.g. to separate deterministic and stochastic parts of daily discharge series $([10])$. [10] estimated two indices, the permutation entropy and the permutation statistical complexity to quantify order pattern distributions by their information content and complexity. Ordinal patterns have been used in other fields of science for pattern recognition e.g. to analyse EEG data ([8]), sunspot numbers ([3]), speech signals ([1]) and chaotic maps ([2]). Further applications include estimation of the Hurst parameter in long-range-dependent data ([19]) and the approximation of the Kolmogorov-Sinai entropy ([9]). Let us emphasize that before [15] appeared, all of the above mentioned authors used ordinal pattern analysis only for a single time series. In difference the ordinal patterns are applied to characterize space-time relationships between runoff series. This methodology is used to estimate the synchronicity of time series of annual runoff means, low water discharges and flood peaks between gauges at different spatial scales. Its potential to characterize long memory processes is shown as well as options to identify anthropogenic changes in runoff series.

\section{Methodology}

When comparing time series one often has to face the following problem: two data series are correlated, but not in the mathematical sense of the word. Let us explain this in detail: in every-day-live, one would say that two data series are positively correlated if the following holds true:

$$
\text { if } X\left\{\begin{array}{l}
\text { increases } \\
\text { decreases }
\end{array}\right\} \text {, then } Y \text { is likely to }\left\{\begin{array}{l}
\text { increase } \\
\text { decrease }
\end{array}\right\} \text {, too. }
$$

Negative correlation would then mean that

$$
\text { if } X\left\{\begin{array}{l}
\text { increases } \\
\text { decreases }
\end{array}\right\} \text {, then } Y \text { is likely to }\left\{\begin{array}{l}
\text { decrease } \\
\text { increase }
\end{array}\right\} \text {. }
$$

Admittedly, in the context of certain models this behaviour is caught nicely by the mathematical correlation between time-series (or their increments). On the other hand it is well known that mathematical correlation measures linear dependence. If data is correlated, but not in a linear way, mathematical correlation might not be the method of choice. Furthermore, in order to deal with mathematical correlation, both time series have to have second moments, that is, the variance has to be finite. Several interesting models, like so called $\alpha$-stable random variables, do not have this property. This means between two $\alpha$-stable time series, we cannot use mathematical correlation. Last but not least in all classical approaches the time series have to be stationary from the beginning (or after a careful pre-processing).

Nevertheless, hydrological time series often are modified by anthropogenic or climatic impacts. Climate variability as well as water management or land-use changes lead to a non-stationary behaviour like changing means or variances in hydrological time series. A reservoir for example has the aim to compensate the fluctuations of runoff at the annual time scale. In this case, especially the upper and lower extremes may show significant changes. Hence, many recent 


\section{Methodology}

results consider the non-stationarity of the data (see [5], [14, [12], [17] and the references therein).

Here, we suggest a simple approach to describe correlation between time series by ordinal patterns ([15], [16]), where the probability measures do not need to have second moments. The time series we consider do not have to be stationary. And: in a certain sense we are able to measure non-linear correlation. The basic idea is to reduce the data to so called ordinal patterns and then count, how often one finds pairwise the same patterns at the same instants of time in two data sets.

\subsection{The specification of ordinal patterns}

For a fixed number of consecutive data points $n$, their ordinal pattern describes the relative positions of the points. Let $x_{1}, x_{2}, \ldots$ be the realized data of a time series. Fix the number of considered data points $n=4$ (often $n \in\{2,3,4,5,6\}$ ), respectively the number of increments $h=n-1$. Let us consider the first four data points $x_{1}, x_{2}, x_{3}, x_{4}$ and assume that the four values are pairwise different, e.g. $x_{1}=2, x_{2}=9, x_{3}=3$ and $x_{4}=11$. Order them top-to-bottom: $x_{4}>x_{2}>x_{3}>x_{1}$. Then write down the indices of the data points in that order: $(4,2,3,1)$. This vector in $\mathbb{N}^{n}$ is called the ordinal pattern of $\left(x_{1}, x_{2}, x_{3}, x_{4}\right)$. We write $\left(r_{1}, \ldots, r_{4}\right)$ for this vector. The pattern $\left(r_{1}, \ldots, r_{4}\right)$ contains the whole information of relative positions of the data points, but nothing more. Therefore, the information is reduced significantly. For each time point $t$ one now has to consider $\left(x_{t+1}, x_{t+2}, x_{t+3}, x_{t+4}\right)$ in the same way. For each starting point $t$ we obtain an $n$-dimensional vector consisting of the entries $1,2,3, \ldots, n$. A vector of this kind is called a permutation.

It could be a problem that for different $i$ and $j$ the measured values of $x_{i}$ and $x_{j}$ do coincide. In order to have a unique representation, we demand in addition:

$$
\text { if } i<j \text { and } x_{i}=x_{j} \text { then } r_{i}<r_{j} \text {. }
$$

For example, in the case $\left(x_{t+1}, x_{t+2}, x_{t+3}, x_{t+4}\right)=(7,10,7,5)$ we would obtain $(2,1,3,4)$ as the ordinal pattern at time $t$.

In order to get a better intuition of the meaning of the permutations, one could in fact think of the patterns as an archetype structure as in the Figure 1.

Instead of the two data sets $x$ and $y$ we, from now on, consider only the sequence of patterns in both time series.

We count how often we find coincident patterns in two series. Coincident patterns do mean that for the given length $n$ (of the time windows) the up-and-down behaviour of the two time series is similar within the two synchronous windows (Figure 2). E.g. if we have $(4,2,3,1)$ this means we start on a low value, increase, go back to a point in between the first two and then have the highest value in the end.

\subsection{A measure to assess the significance of coincidences of ordinal patterns between two times series}

In the second step, we estimate a measure to compare the number of coincident patterns with its random value. This comparison value is obtained in the following way: we assume for a moment that the two time series are independent. Let us denote by $P_{X}(r)$ the probability that the pattern $r$ appears in the time series $X$ (same with $Y$ ). In the case $h=3$ we would have the 24 different patterns that are shown in Figure 1. If the time series were independent, the probability that $r$ appears in both time series at the same time would be $P_{X}(r) \cdot P_{Y}(r)$ and the 


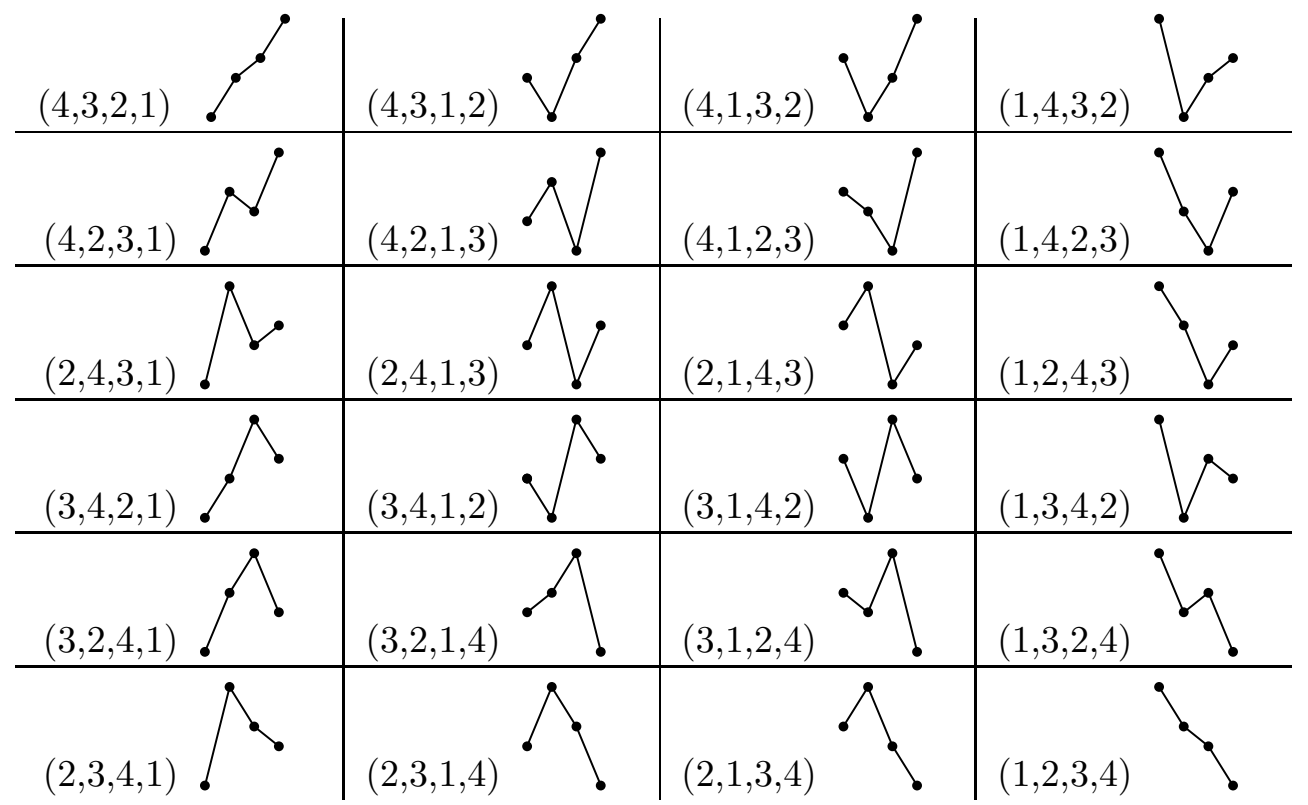

Figure 1: The 24 ordinal patterns of length $4(h=3)$

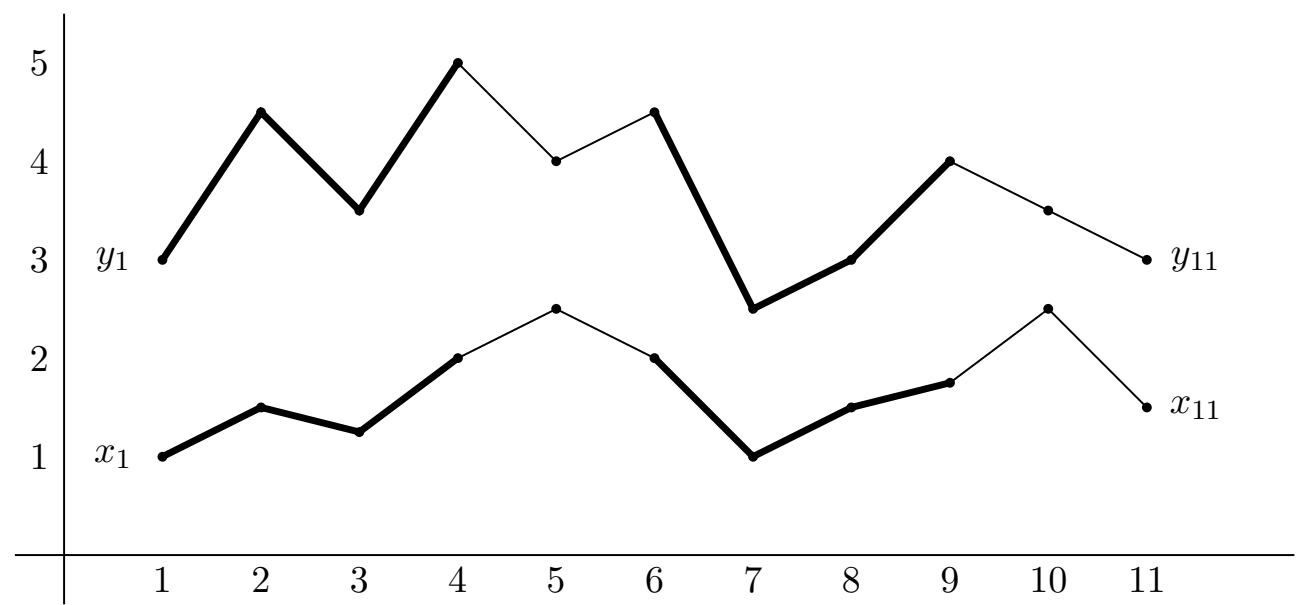

Figure 2: Example of the ordinal patterns of two time series. 


\section{Methodology}

overall probability to find the same pattern in both time series at a given time would be:

$$
q:=\sum_{r=\left(r_{1}, \ldots, r_{n}\right)} P_{X}(r) \cdot P_{Y}(r)
$$

where we sum over all patterns $r$ of length $n$. This is only a theoretical construct. Caused e.g. by seasonality, some patterns will occur more often in hydrological time series than others. Empirically, for each time series we estimate the empirical probabilities of the single patterns by their relative frequencies. The comparison value $v_{c}$ is the estimator of $q$, based on relative frequencies of the patterns in both time series multiplied with $(N-h)$, where $N$ is the number of observations. This means: The comparison value $v_{c}$ is the number of coincident patterns which we would expect if the time series were independent.

$$
v_{c}=(N-h) \sum_{r=\left(r_{1}, \ldots, r_{h+1}\right)} \hat{P}_{X}(r) \cdot \hat{P}_{Y}(r)
$$

where $\hat{P}_{X}(r)$ denotes the relative frequency of the pattern $r$ in the sample $X$.

Let us recall some of the advantages of the method which have been emphasized in [16]: the whole analysis is stable under monotone transformations of the state space. The ordinal structure is not destroyed by measurement errors or small perturbations of the data. Structural breaks in a single time series do not effect the ordinal pattern dependence significantly. There are fast algorithms to analyse the relative frequencies of ordinal patterns in given data sets (cf. [7], Section 1.4). Furthermore, let us again emphasize that unlike other concepts which are based on mathematical correlation, we do not have to impose the existence of second moments. This allows us to consider a bigger variety of model classes. Last but not least, our concept is more intuitive, than using Kendall's tau or Spearman's rho ([18]).

\subsection{Criteria of similarity among patterns by a metrical approach}

A drawback of the method described above is that we only count the number of completely coinciding patterns. In particular, if $n$ is large we will find maybe several instants in time where the patterns are 'almost similar'. Schnurr and Dehling (2015) proposed a method to overcome this problem. To this end, distances between ordinal patterns are measured and weight functions are used.

The procedure consists of the following steps: At first we introduce a so called metric on the space of ordinal patterns, that is, a function $d$ which describes how far away two ordinal patterns are from each other. The mathematical definition is as follows: let $r$ and $s$ be permutations of length $n$ and set

$$
d(r, s):=\left|r_{1}-s_{1}\right|+\ldots+\left|r_{n}-s_{n}\right| .
$$

If the up-and-down behaviour of two patterns is similar one gets a small number for $d$. Coincident patterns yield $d(r, r)=0$. We would like to calculate a kind of score with the opposite property, i.e., coincident patterns should be assigned the number 1 while patterns which are close to each other should get a number less than (but close to) 1. Finally, patterns that are far away from each other should get the value zero. The above metric $d$ yields only even numbers as values. Instead of using $d$ directly, we use the following anti-monotone weight function on the values of $d$ : 


$$
w(x):=1 \cdot 1_{\{x=0\}}+0.75 \cdot 1_{\{x=2\}}+0.5 \cdot 1_{\{x=4\}}+0.25 \cdot 1_{\{x=6\}},
$$

where $1_{\{x=t\}}$ is the indicator function, being one, when $x=t$, and zero else. Note, that this function is defined especially for small $n$. For larger $n$ an appropriate weight function has to be defined, for example by using smaller steps of weights.

As our score we set:

$$
s(r, s):=w \circ d(r, s)=w(d(r, s))
$$

This score has the desired property. Coincident patterns yield $s(r, r)=1$ and the bigger the distance between the patterns, the lower the score. As in the classical case described above, we compare the score with a comparison value $v_{c, w}$. This comparison value $v_{c, w}$ is (again) the score, which we would expect if $X$ and $Y$ were independent. In the following this methodology is called the metrical approach.

\subsection{Pre-processing, considering data uncertainty}

A specific problem when considering real data sets is the uncertainty of the data. Uncertainty of discharges can arise e.g. from errors in measurement, especially from uncertain stage-discharge relationships. Especially for low discharges occasional deviations from the real value can occur. The classical ordinal pattern approach would declare two patterns as unequal if in both patterns synchronously two consecutive values would deviate with the value $\epsilon$, but in the one case the one value is larger by the factor $\epsilon$ and the other one it is smaller. If $\epsilon$ is small, this different behavior could result from data uncertainty. For such cases, we do not want to categorize the patterns as different. Thus, we need a method to consider these possible sources of uncertainty and take them into account in the ordinal pattern approach. We call this procedure pre-processing.

For every time step $t$ we consider the subsample $x_{t+1}, x_{t+2}, \ldots, x_{t+n}$. If for any $i=1, \ldots, n-1$

$$
\frac{x_{t+i+1}}{x_{t+i}} \in[1-\epsilon, 1+\epsilon]
$$

for $\epsilon \geq 0$ we define the pattern of $x_{t+1}, x_{t+2}, \ldots, x_{t+n}$ to be partly random.

If at least one of the patterns $r^{t}, s^{t}$ at time step $t$ of the two compared time series is partly random, replace $s\left(r^{t}, s^{t}\right)$ by $\max \left(s\left(r^{t}, s^{t}\right)-1 / 4,0\right)$. For the non-metrical approach we simply count the coherence by 0.75 instead of 1 . Since the uncertainty is very high when considering extreme discharges (flood peaks, low water), for these cases $\epsilon$ is chosen as 0.1 , whereas for mean discharges (MQ) it is 0.05 .

When using pre-processing this also influences the comparison value. Hence, the calculation of it changes in this case. First we have to estimate the probability $p_{X}$ that a pattern in sample $X$ is partly random by the relative frequency. Considering two samples $X$ and $Y$ the probability that at arbitrary time at least one sample is partly random is then

$$
z=p_{X}+p_{Y}-p_{X} \cdot p_{Y}
$$

For the classical approach we now have to take into account that with probability $z$ the weight of the coincidence is reduced to 0.75 whereas it remains 1 with probability $(1-z)$. This leads to a mixing-type calculation of the comparison value denoted with $v_{c, p p}$. 


\section{Methodology}

In the metric approach we have to consider that, if we have a partly random pattern, the weight is reduced by 0.25 . The modified metric then is defined as

$$
\begin{aligned}
w_{z}(x):= & (1(1-z)+0.75 \cdot z) \cdot 1_{\{x=0\}}+(0.75(1-z)+0.5 \cdot z) \cdot 1_{\{x=2\}} \\
& +(0.5(1-z)+0.25 \cdot z) \cdot 1_{\{x=4\}}+(0.25(1-z)+0 \cdot z) \cdot 1_{\{x=6\}}
\end{aligned}
$$

and the comparison value $v_{c, p p w}$ is calculated as before using this new metric.

\subsection{Introducing example}

To demonstrate the application of the methodology described above, we compare series of annual flood peaks in winter from two gauges (Golzern and Bad Dueben) which are located in line at the same river (Mulde River in South-Eastern Germany). The Golzern gauge has a catchment of $5433 \mathrm{~km}^{2}$ in size, the Bad Dueben gauge of $6170 \mathrm{~km}^{2}$. Table 1 shows winter maximum discharges from 6 years. Both time series differ as the discharge estimation in Bad Dueben is more erroneous than at the Golzern gauge.

Table 1: Annual winter maximum discharges $\left[\mathrm{m}^{3} / \mathrm{s}\right]$ for the years 1961-1966 of the gauges Golzern and Bad Dueben

\begin{tabular}{lll}
\hline & Golzern & Bad Düben \\
\hline 1961 & 402 & 347 \\
1962 & 218 & 209 \\
1963 & 595 & 354 \\
1964 & 336 & 134 \\
1965 & 410 & 403 \\
1966 & 236 & 287 \\
\hline
\end{tabular}

As shown by Table1, for smaller flood events the downstream gauge delivers smaller flood peaks than the upstream gauge. Note that for this subsample no pre-processing is necessary.

If we want to calculate the ordinal pattern with number of increments $h=4$ (that is number of data $n=5)$ for the first sub-sample $\left(X_{1}, X_{2}, X_{3}, X_{4}, X_{5}\right)$ we have to calculate the order of the indices of the data for this sub-sample. For the Golzern gauge the first sub-sample is $(402,218,595,336,410)$, that is $X_{3}>X_{5}>X_{1}>X_{4}>X_{2}$ resulting in the ordinal pattern $r^{(1)}=(3,5,1,4,2)$. This is compared with the ordinal pattern of the first $n=5$ data of the Bad Dueben gauge $s^{(1)}=(5,3,1,2,4)$. We can see that there is no match between the patterns. Now the next possible sub-sample $\left(X_{2}, X_{3}, X_{4}, X_{5}, X_{6}\right)=\left(X_{1}^{\prime}, X_{2}^{\prime}, X_{3}^{\prime}, X_{4}^{\prime}, X_{5}^{\prime}\right)$ is considered, that is for Golzern $(218,595,336,410,236)$ with $X_{2}^{\prime}>X_{4}^{\prime}>X_{3}^{\prime}>X_{5}^{\prime}>X_{1}^{\prime}$ and resulting ordinal pattern $r^{(2)}=(2,4,3,5,1)$ and for Bad Dueben $(209,354,134,403,287)$ with ordinal pattern $s^{(2)}=(4,2,5,1,3)$. Again there is no match and we can go on to the next sub-sample and so on.

The first coincidence can be found when comparing the seventh subsample $\left(X_{7}, X_{8}, X_{9}, X_{10}, X_{11}\right)=$ $\left(X_{1}^{\star}, X_{2}^{\star}, X_{3}^{\star}, X_{4}^{\star}, X_{5}^{\star}\right)$ of the Golzern gauge (Table 2).

The ordinal pattern appears to be $r^{(7)}=(2,4,1,3,5)=s^{(7)}$ and we find a match. After comparing all 49 sub-samples 30 matches between the ordinal patterns were found. This indicates a very high coherence between the flood behaviour of both gauges. Of course, this is not so surprising since both gauges are located consecutively and no larger tributary enters in between. Therefore, the relative contributions of runoff from the catchment between both gauges is small. 


\section{Methodology}

Table 2: Annual winter maximum discharges $\left[\mathrm{m}^{3} / \mathrm{s}\right]$ for the years 1967-1971 of the gauges Golzern and Bad Düben

\begin{tabular}{lll}
\hline & Golzern & Bad Düben \\
\hline 1967 & 354 & 357 \\
1968 & 623 & 684 \\
1969 & 319 & 280 \\
1970 & 477 & 465 \\
1971 & 224 & 197 \\
\hline
\end{tabular}

We mentioned in the description of the methodology that it is not always useful to only compare exact matches of patterns. Especially when considering hydrological time series with periods of extreme small or high discharges, the ordinal patterns are affected by errors in discharge estimation such that small deviations in the patterns should not automatically be rejected. Here we use the metrical approach of ordinal patterns. For the example above we have to calculate the score (see eq. (5) )

$$
\begin{aligned}
s\left(r^{(1)}, s^{(1)}\right)= & 1 \cdot 1_{\left\{d\left(r^{(1)}, s^{(1)}\right)=0\right\}}+0.75 \cdot 1_{\left\{d\left(r^{(1)}, s^{(1)}\right)=2\right\}} \\
& +0.5 \cdot 1_{\left\{d\left(r^{(1)}, s^{(1)}\right)=4\right\}}+0.25 \cdot 1_{\left\{d\left(r^{(1)}, s^{(1)}\right)=6\right\}} \\
= & 0
\end{aligned}
$$

since

$$
d\left(r^{(1)}, s^{(1)}\right)=|3-5|+|5-3|+|1-1|+|4-2|+|2-4|=8
$$

and analogously

$$
d\left(r^{(2)}, s^{(2)}\right)=12 \Longrightarrow s\left(r^{(2)}, s^{(2)}\right)=0 .
$$

This means that the first ordinal pattern of Golzern is more similar to the first pattern of Bad Dueben than both second patterns are, but we still give zero weight to the pattern since the difference is too large. This coincides with the intuitive classification of the coherence when only looking at the data. If we sum up the numbers for all patterns we get

$$
S=\sum_{i=1}^{49} s\left(r^{(i)}, s^{(i)}\right)=42 .
$$

The pre-processing has to be applied if in both series a large number of values are located within the same moderate range. In such cases small differences between these values are random and can be caused by errors in measurements. Therefore, these small differences should not influence the detected coherence. For the two subsamples above the pre-processing does not have to be applied since all two consecutive values of a sample differ with more than $10 \%$. For all of the 51 pairs of consecutive values we find 4 that only differ with less than $10 \%$ for Golzern and 3 for Bad Dueben, where this occurs two times at the same time step for Golzern and Bad Dueben. All in all 20 of the 49 possible patterns are declared as partly random and we only count 16 coincident patterns. That is, for the non-random patterns we have a coincidence of $55.17 \%$.

To compare both series, the comparison value has to be calculated by summarising the multiplied empirical frequencies of each possible pattern. For example, the pattern $r^{(1)}=(3,5,1,4,2)$ can be found in one of the 49 sequences for the Golzern gauge (in the first possible subsample) and also for one sequence at the Bad Dueben gauge. Therefore, the joint probability under 


\section{Application}

assumption of independence is the sum term $1 / 49 \cdot 1 / 49=1 / 2401=0.000416$. The pattern $r^{(2)}=(2,4,3,5,1)$ appears twice in the sample of the Golzern gauge and not at all in the sample of Bad Dueben. This leads to a sum term of 0 for the calculation of the comparison value. After doing this for all 120 possible patterns, the single sum terms are summarised and multiplied with the number of subsamples (here 49) to get the comparison value $v_{c}=49 \cdot 0.0503=2.47$. If the Golzern and Bad Dueben gauges were independent, we would expect only 2 to 3 (exactly 2.47) coincidences of the patterns. Actually, we find 30 coincidences. That is, the Golzern and Bad Dueben gauges show a significant deviation and cannot be assumed to be independent.

Additionally, one can also calculate the comparison value for the metrical approach of ordinal patterns. In this case, not only the frequencies of one pattern for both samples are multiplied, but all possible combinations of patterns in both samples. This is then weighted by using the weighting function in eq. (4). For the gauge pair Golzern and Bad Dueben we get a comparison value $v_{c, w}=7.199$ that can be compared with the number of coincidences under the metrical approach of 35.25 .

For the comparison value under pre-processing $v_{c, p p}$ we have to calculate the empirical frequency of a random pattern $z$. Since $p_{X}=16 / 49=0.327$ and $p_{y}=12 / 49=0.245$ we have $z=0.492$. Thus $v_{c, p p}=(1-z) \cdot v_{c}+z \cdot\left(v_{c}^{\prime}\right)=1.98$, where $\left(v_{c}^{\prime}\right)$ is the comparison value based on the reduced coherence of 0.75 . This means, for $v_{c}^{\prime}$ we do not calculate a pattern with one in the sum of eq. (2) but with 0.75 if it is partly random.

\section{Application}

To test the applicability of ordinal patterns to characterize differences and similarities of the runoff regime at different spatial scales and different runoff characteristics we use several examples:

- Series of flood peaks from 19 mesoscale catchments which belong to the same river basin are compared for the Mulde River Basin, which has a total area of $6171 \mathrm{~km}^{2}$

- Pairwise comparisons of discharge series from catchments which are located in different but adjacent river basins

- Runoff series from large catchments (area between 47496 and $144232 \mathrm{~km}^{2}$ ) in different parts of Germany.

\subsection{Comparison of flood series within one river basin}

Beside these differences in catchments size and neighbourhood, different runoff characteristics were analysed. For the 19 mesoscale catchments series of the winter and summer floods were compared. We analysed annual winter and summer maximum discharges of several gauges within the river basin Mulde in Eastern Germany (Figure 3). The Mulde river basin is located in Saxony and has a catchment area of $6170 \mathrm{~km}^{2}$ (at the Bad Dueben gauge). The Mulde River is a tributary of the Elbe river and consists itself of three main sub-catchments, Zwickauer Mulde, Zschopau and Freiberger Mulde. The mountainous head areas are located at the foothills and hilly country of the low mountain range Ore mountains leading to an amount of $1 / 3$ of the whole area being mountains and $2 / 3$ being lowlands $(<500 \mathrm{~m}$ a.s.l.) ([13]). The highest rise is the Fichtelberg mountain with $1214 \mathrm{~m}$ a.s.l.. 


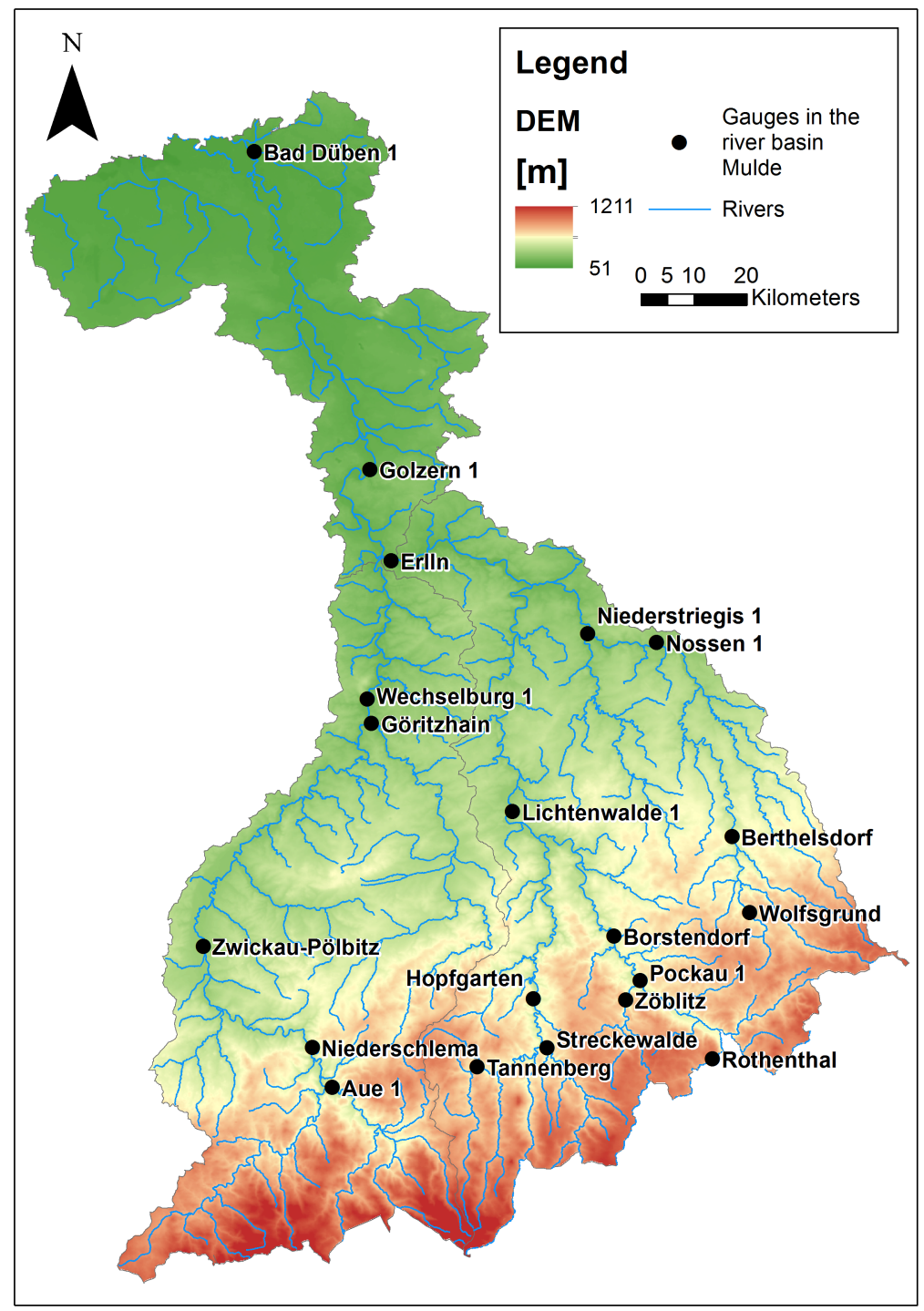

Figure 3: The Mulde river basin in Eastern Germany

\subsubsection{Flood series}

The data base consists of annual winter (November-April) or summer (May-October) maximum discharges measured at 19 gauges in the Mulde basin during the time period 1961 to 2013. As it is possible only to compare time series of the same observations period some series were shortened to a common time period. For all gauges the ordinal patterns were calculated pairwise with the number of increments $h=4$ and the number of consistent patterns was counted.

The degree of coincidence of a gauge was obtained by comparison to other pairs of gauges. To evaluate the coincidences we apply the comparison value $v_{c}$ (eq. (2)). A coincidence of more than $10 \%$ is statistical significant in the sense that it is more than $50 \%$ higher than a random coincidence under independence of both time series.

An overview over all calculated coincidences (in \%) with pre-processing and application of the metrical approach for the annual winter maxima in the Mulde river basin can be found in Table 


\section{Application}

6) (above the main diagonal) in the Appendix. The colour of cells was chosen to separate three classes (high, medium, low coincidence). It becomes obvious that the series of winter floods (part of the table above the main diagonal) shows more coincidences than series of summer floods. The same pattern of coincidence can be found, regardless of using the simple or the metrical approach, although the coincidence within the single sub-catchments is larger for the metrical approach. The usage of the metrical version, where small deviations between patterns are taken into account, seems in this case favourable. It was applied for all calculations which are presented by their results below.

From Table 6 we see that a slight coincidence exists between most of the gauges in winter. This indicates that there are winter events, which influence the whole river basin at the same time. This is the result of winter flood events which are mainly caused by stratiform rainfall or by snow melt in spring. For the annual summer maximum discharges of the 19 gauges (values below the main diagonal) in the Mulde basin, the tendential relations of the coincidences remain similar. However, the number of coincidences above 30 percent is lower in general. This can be explained by more localized rain events inducing floods in summer, which only affect parts of the river basin. We can also see that nearly all gauges coincide with the all-embracing Golzern gauge by more than 30\%, where the Nossen, Niederstriegis, Erlln and Lichtenwalde gauges have the largest coincidence. Among the gauges that show a coincidence of less than 30 percent with Golzern gauge are the Goeritzhain gauge that is strongly affected by urbanization which becomes evident in connection with convective rain cells in summer and the Streckewalde gauge, where the summer flood peaks are affected by a reservoir. Gauges which do not belong to the same sub-basin and therefore are rather far away from each other do not show any coincidence. This indicates that there are only few or none summer events, which influence the whole catchment area at the same time.

To compare patterns of discharges within a river basin the spatial relationships between gauges have to be considered. Here we differentiated between gauges which are arranged in series or parallel. In the first case, if two gauges are located in line, the coincidence of patterns depends on the impact of the intermediate catchment, in the second case, if the catchments are parallel situated (which seems to be more interesting here), it depends on the similarity of rainfall and runoff formation between the watersheds. Coinciding patterns characterize the similarity of series at gauges downstream with their tributaries and difference of their runoff synchronicity with the main river. To give an example in Figure 4 the pairwise coincidence between gauges in the lower part of the basin is shown. The tree structure of the river network, the catchment size and the percentages of coinciding patterns for winter and summer floods are visualized. It can be seen that the percentages, characterizing the degree of coincidence, are higher in winter than in summer. The high coincidence of the series of winter floods at the Erlln gauge with the series at Nossen gauge and the lower ones between Erlln and Lichtenwalde demonstrates, that similarities between flood series in winter depend not necessarily on the catchment size. The series of summer floods at the Goeritzhain gauge shows a different behaviour if it is compared with the summer flood series at the Wechselburg or Zwickau gauges. As mentioned above, this is caused by a large urbanized part of this catchment, which reacts directly on rainfall events summer and modifies the series of summer floods peaks.

For both studies, using simple ordinal patterns and metrical ordinal patterns, it is striking that the Aue 1 gauge shows no coincidence above 30\% with any other gauge in the basin for winter floods. This small catchment with its special location in the Western part of the Ore mountains seems to have a different flood behaviour during winter than the gauges located in the Eastern part of the Ore mountains. A visual presentation of the detected pairwise coherences between the gauges can be found in Figure 5 for winter floods and in Figure 6 for summer floods. For 


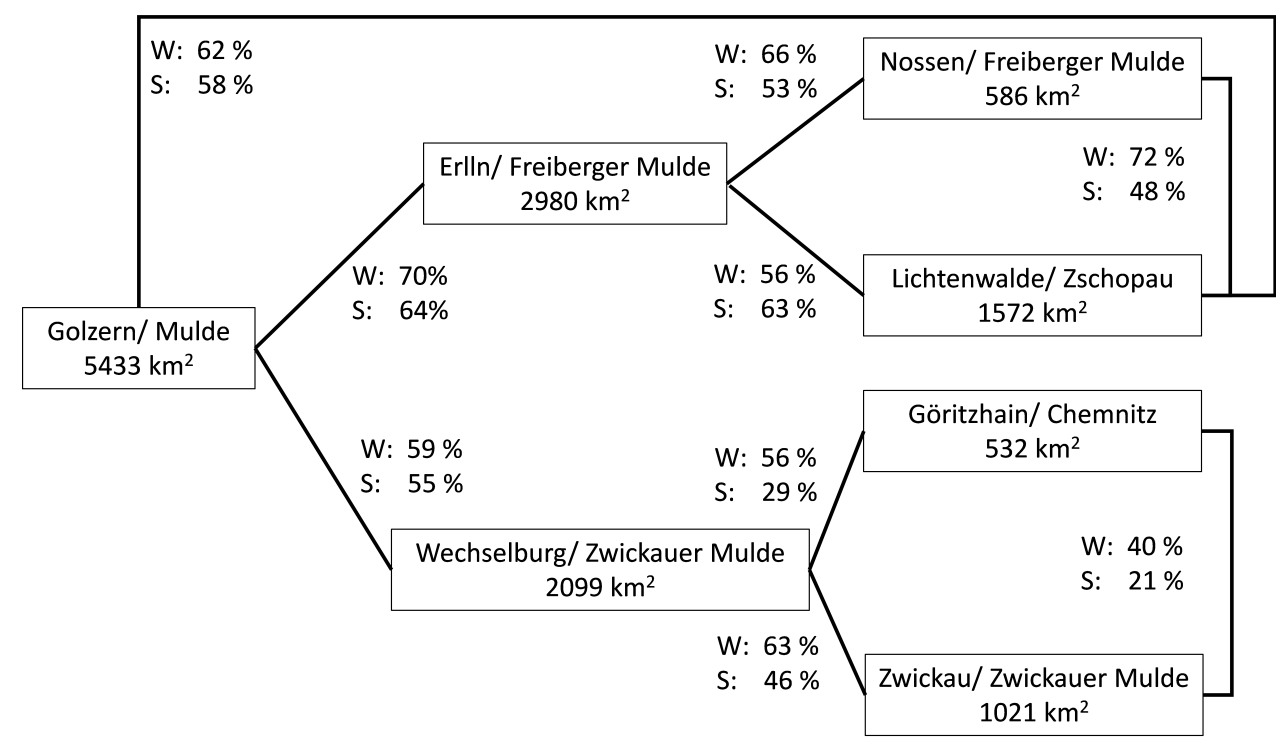

Figure 4: Pairwise coincidences of the lower parts of the Mulde river basin.

every gauge the inner circle indicates the colour of the gauge and the colours of the outer circle are the gauges for which a significant coherence is detected. For a better readability, we only show coherences larger than $50 \%$. It becomes obvious that the catchments of headwaters show less coincidences of flood series than the catchments with larger drainage areas located downstream.

The results show that the maximum floods in summer as well as in winter in general exhibit a local behaviour, that can be explained by the climatic conditions, especially the different types of flood events (see [6]). Similar results were also detected by e.g. [13] using circulation patterns. The results for summer floods demonstrate the highest coincidences between gauges which lie very close together, in fact no more than $30 \mathrm{~km}$ measured as Euclidean distances between the centres of the catchment areas. Additionally, one can find coincidences of nearly all gauges in a basin with the discharge series at the basin outlet (Golzern gauge) as it is shown in Figure 7 .

Again, we can see for the summer as well for the winter annual maxima a decreasing progression for increasing area relation of the catchment, related to the area of the catchment Golzern. Consider that the abscissa is subdivided in a logarithmic scale. The coincidences decrease with the ratio of areas. They are higher in winter. The differences between winter and summer coincidences scatter. E.g. the coincidence of the gauge Goeritzhain with Golzern is in winter close to the average (blue line) but in summer much lower. In difference the gauge Aue shows a coincidence with gauge Golzern in summer but not in winter. The distribution of magnitude of coincidences within the Mulde river basin implies the assumption that the distance of the gauges plays a crucial role for the coincidence. Of course, gauges that are located in row within the basin tends to have a more similar behaviour than gauges that are parallel. But at least the winter annual maxima show coincidences between gauges with parallel catchments that are located close together. We therefore want to have a closer look at the relation of the distance between the centroids of the catchments and the coincidence. For this we use the distance of the centroids of the single catchments and compare all gauges that are parallel and head water catchments. The results can be found in Figure 8 , 


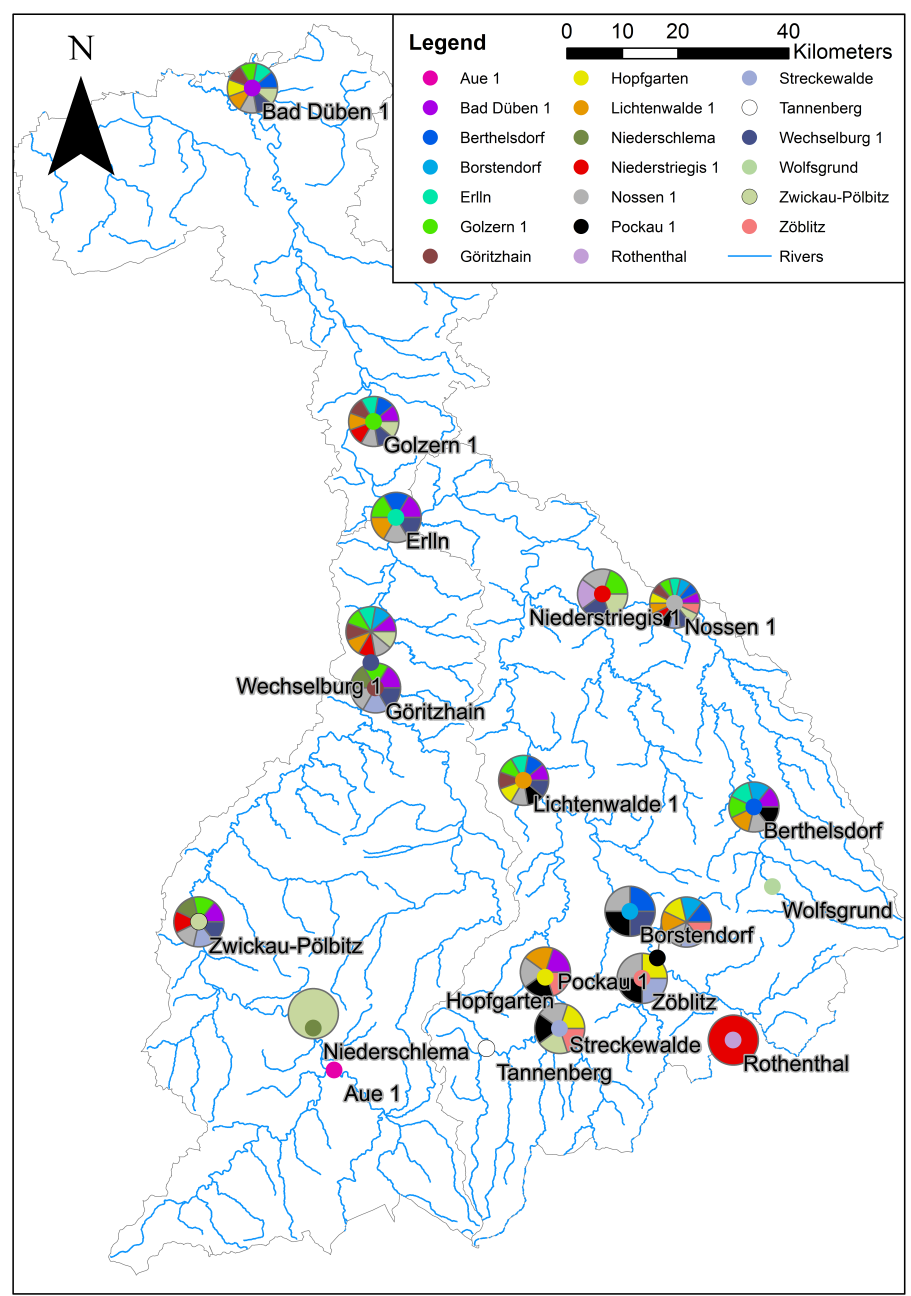

Figure 5: Coherences of patterns in the winter annual maxima of the Mulde river basin.

We can see a linear relationship between the distance and the coincidence of the winter annual maxima. With increasing distance the coincidence decreases as one would expect. For the summer annual maxima no such relationship can be found. The applicability of ordinal patterns to estimate changes of the flood regime by human intervention can be demonstrated by an application for the gauge Streckenwalde. The time series at this gauge which dates back to 1921 is affected by a new-built reservoir since 1973. By comparison with the flood series at the gauge Hopfgarten for the same time period, a break point of coincidences becomes evident (Table 3i). The coincidence of the summer floods is reduced by operation of the reservoir especially in summer time.

\subsection{Comparison of series of mean discharges and low water discharges at different spatial scales}

Annual mean discharges are an indicator for the annual weather conditions, whereas low water discharges indicate dryness and evapotranspiration. Both hydrological characteristics depend on weather conditions for time periods of several months, which are similar on the regional scale. To characterize differences and similarities of these characteristics, the developed method 


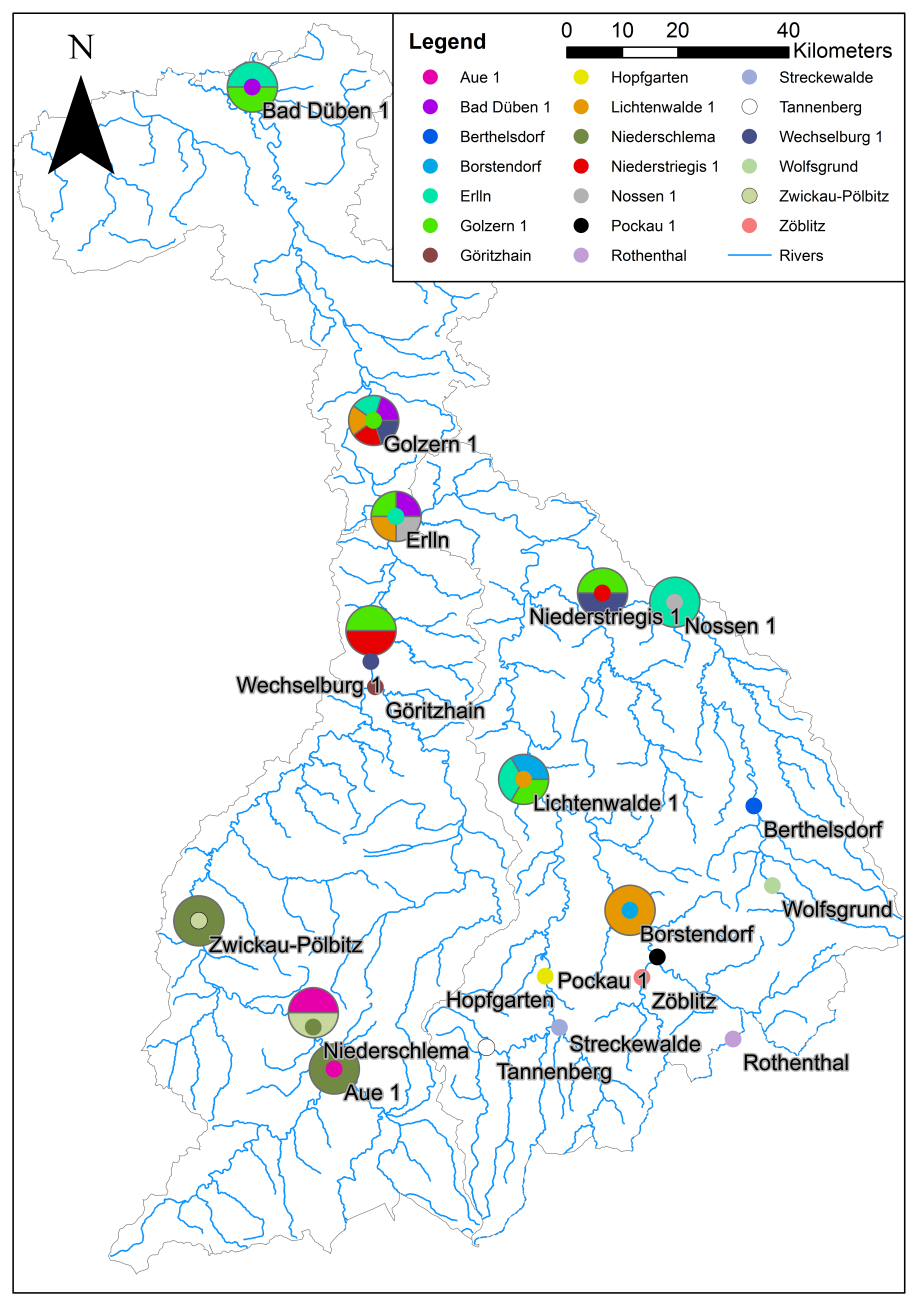

Figure 6: Coherences of patterns in the summer annual maxima of the Mulde river basin.

of ordinal patterns was applied to annual mean discharges and discharge means during low water periods. Here we used the annual minimum of moving averages of mean discharges over $D$ days in one year (NMDQ). If the catchment area of a gauge is smaller than $1000 \mathrm{~km}^{2}$ we considered a time span of $D=7$ days otherwise of 30 days.

To analyse the differences in similarities of runoff series, we used pairwise comparisons of discharge series from catchments, that are located in the Mulde Basin, from adjacent catchments in the same geographical region (Saxony) and from large catchments in different parts of Germany. To estimate coincidences in a regional approach, we have considered a data sample consisting of three pairs of gauges located in different basins all over Saxony, belonging all to river systems entering the Elbe. The pairs were chosen by the similarity of the catchment size. We chose the pairs Aue 1 (Zwickauer Mulde)-Adorf (Weisse Elster), Wechselburg (Zwickauer Mulde) Spreewitz (Spree) and Nossen 1 (Freiberger Mulde) - Merzdorf (Elbe) (Figure 9) with sample length of 50 up to 90 years. In the following, we will call this sample the Saxony-sample.

As a more global sample, we chose gauges from three of the main rivers in Germany. The gauges Cologne, Maxau (both Rhine), Neu-Darchau, Dresden (both Elbe) and Hofkirchen (Danube) are located all over Germany (Figure 10) and have a sample length of about 100 up to 200 


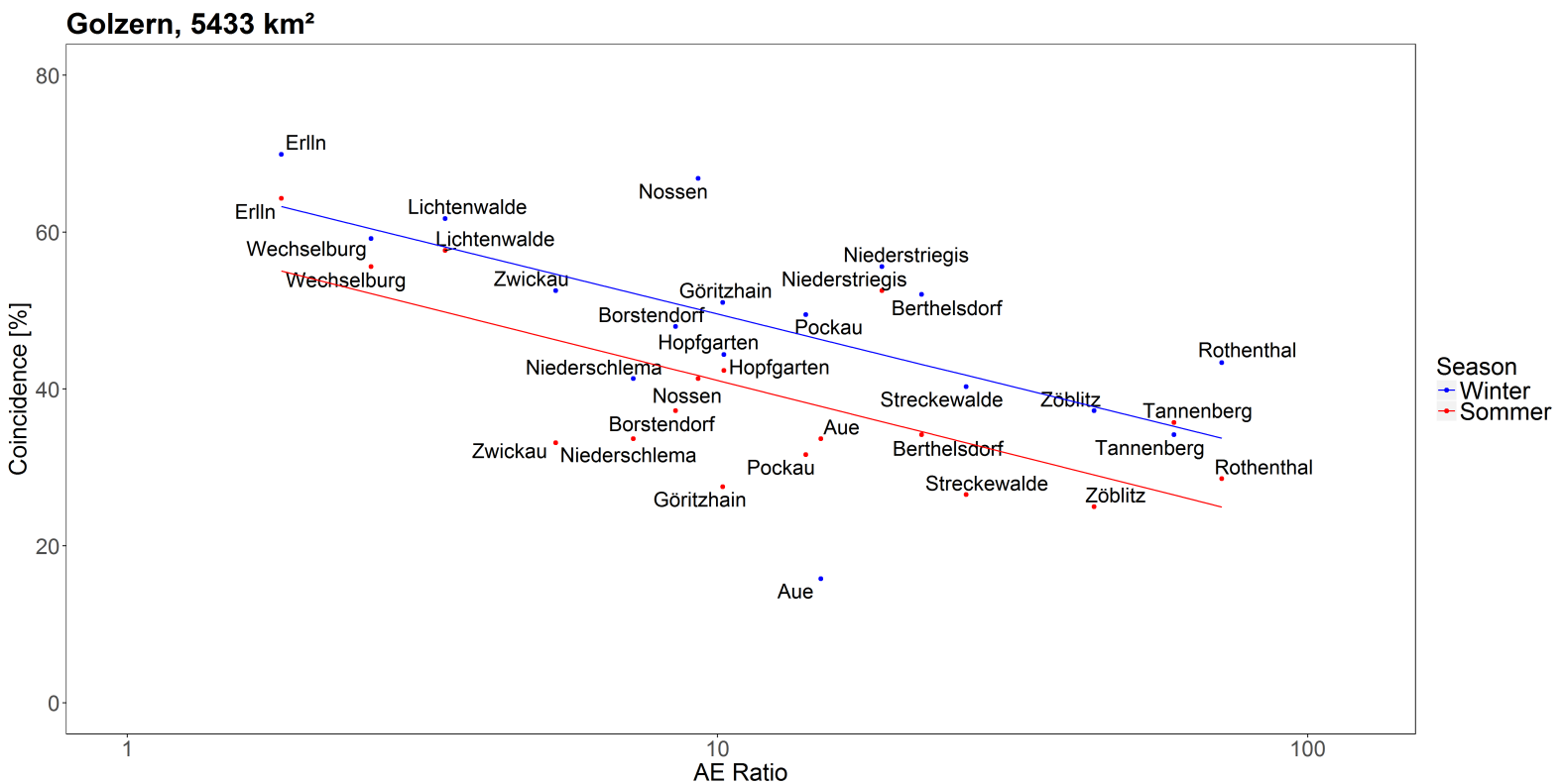

Figure 7: Relation of the catchment size quotient to the coincidence with the gauge Golzern for the whole Mulde river basin.

Table 3: Coincidence of the Hopfgarten and Streckewalde gauges before and after the building of a dam in 1972 .

\begin{tabular}{c|cc} 
Coincidence in $\%$ & from 1921 to 1971 & from 1972 to 2014 \\
\hline Winter floods & 23 & 18.5 \\
Summer floods & 31.25 & 11.25
\end{tabular}

years. We will call this the Germany-sample.

Additionally, we compared the global samples with pairs of gauges of the Mulde river basin having similar catchments. In the evaluation of the results we will concentrate on the case $h=4$, that is four increments or five data points, and the metric approach with pre-processing compared with the corresponding comparison value $v_{c, p p w}$.

The row $v_{c, p p w}$ gives the random coincidence under assumption of independence, the row relation the multiple of this number reached by the coincidence value. To give an example: The annual mean discharges of the gauges Hofkirchen/Danube and Maxau/Rhine with a common sample length of 86 years have $39.63 \%$ coincidence of the length $h=4$, where we would expect under independence $7.70 \%$ (remember that we used the metrical approach and pre-processing). The relationship between both values is 5.15. Likewise, the gauges Wechselburg/Zwickauer Mulde and Spreewitz/Spree have $37.79 \%$ coincidence ( $7.61 \%$ expected under independence), leading to a relation of about 5 between observed and expected percentage number of coincidences. This means, we have five times more coincidences than one would expect under independence. A relation between about 4 and 5 can be found for all pairs of gauges in the sample Saxony. Also for the Mulde sample these relation differs distinctly. Nevertheless, there are also gauge pairs with a small relation. For example the Berthelsdorf and Niederschlema gauges, which are also located close together but belong to different sub-basins, have only a relation of percentage coincidence of 3.93. This can be explained by a reservoir which increase the low water at the 


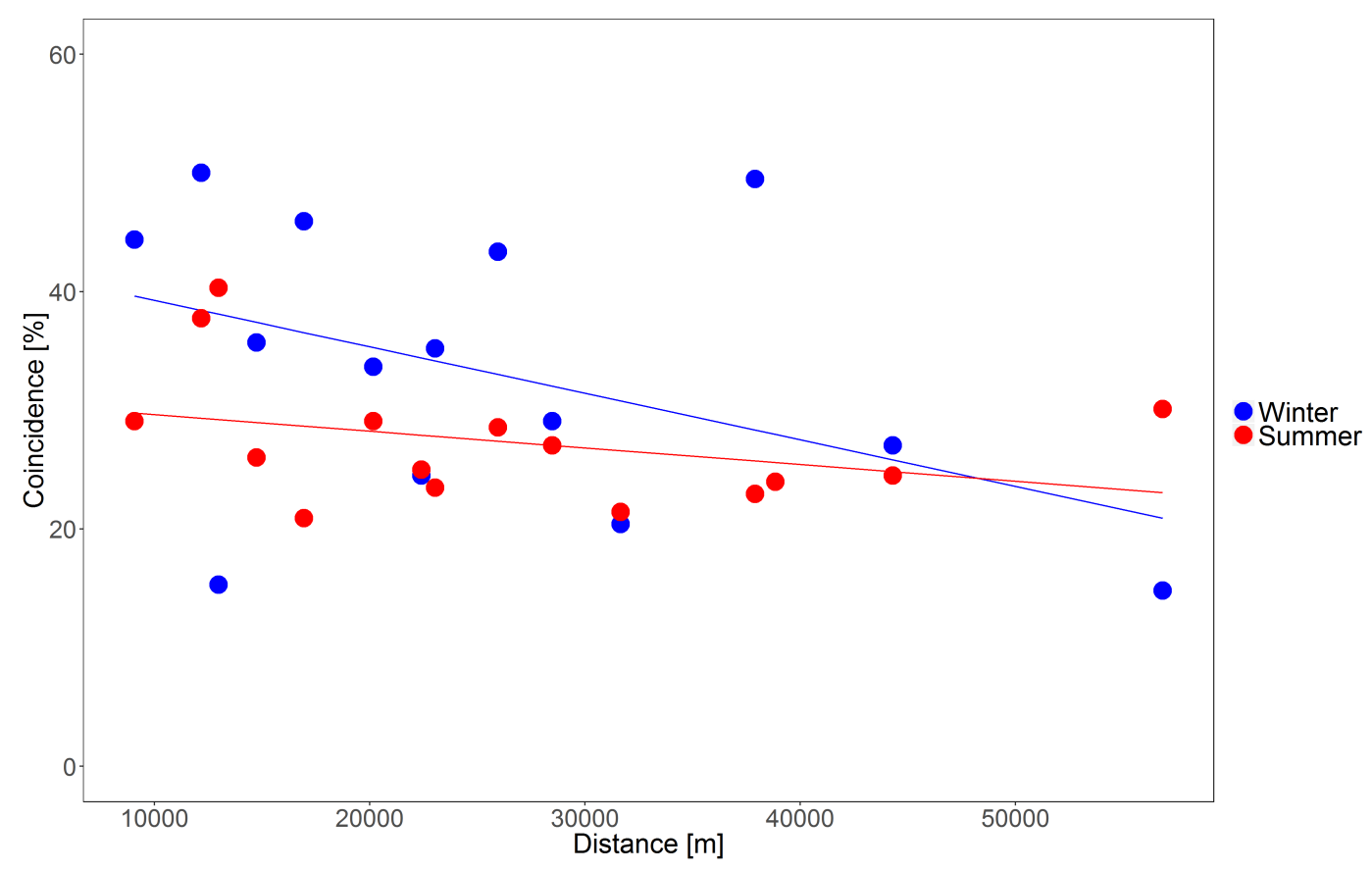

Figure 8: Relation of the distance and the coincidence for all head water catchments.

Niederschlema gauge since 1980. For all pairs of gauges in the Mulde river basin we can find coherences whose number is significantly higher than one would expect under independence. For example the Hopfgarten and Niederschlema gauges mentioned $54.91 \%$ of the mean discharges behave alike where we would expect a coherence of $8.11 \%$. This behaviour can be also found for the gauges in geographical region Saxony but with lesser coherence, though still highly significant. All gauges are located close together in a distance of at most $150 \mathrm{~km}$ (concerning the gauge) and belong to the Elbe system.

For the Germany sample this relation varies much between a lowest value of 2.49 and the largest value of 8.15. The results show that the mean charges have very similar behaviour within a river basin (Table 2).Even for the sample of gauges located all over Germany the detected number of coherences is much higher than one would expect under independence. That is, we can find a noticeable similar behaviour in the mean discharges. Especially gauges belonging to the same river (Cologne and Maxau/Rhine and Neu-Darchau and Dresden/Elbe) have an extremely large number of coherences. Surprisingly, gauges belonging to different basins show in some cases (Cologne/Rhine versus Hofkirchen/Danube) an almost as high relation as rivers of the same basin (Neu-Darchau/Elbe versus Dresden/Elbe). Nevertheless, the coincidences behave disconcordantly. That means, if the series at gauge $\mathrm{A}$ has a high coincidence with the series $\mathrm{B}$ and gauge $\mathrm{B}$ with gauge $\mathrm{C}$, this does not imply that gauges $\mathrm{A}$ has also a high coincidence with gauge $\mathrm{C}$.

In general the results show that the series of mean discharges show a more similar behaviour for all gauges compared to floods. That is, the annual average discharge at gauges behaves nearly the same, regardless of the distance of the gauges. Of course there are gauges, where the coincidence is higher (these are mostly gauges, which lie closely together - Golzern- Bad Dueben, Niederschlema-Hopfgarten, or gauges belonging to the same river - Cologne-Maxau 


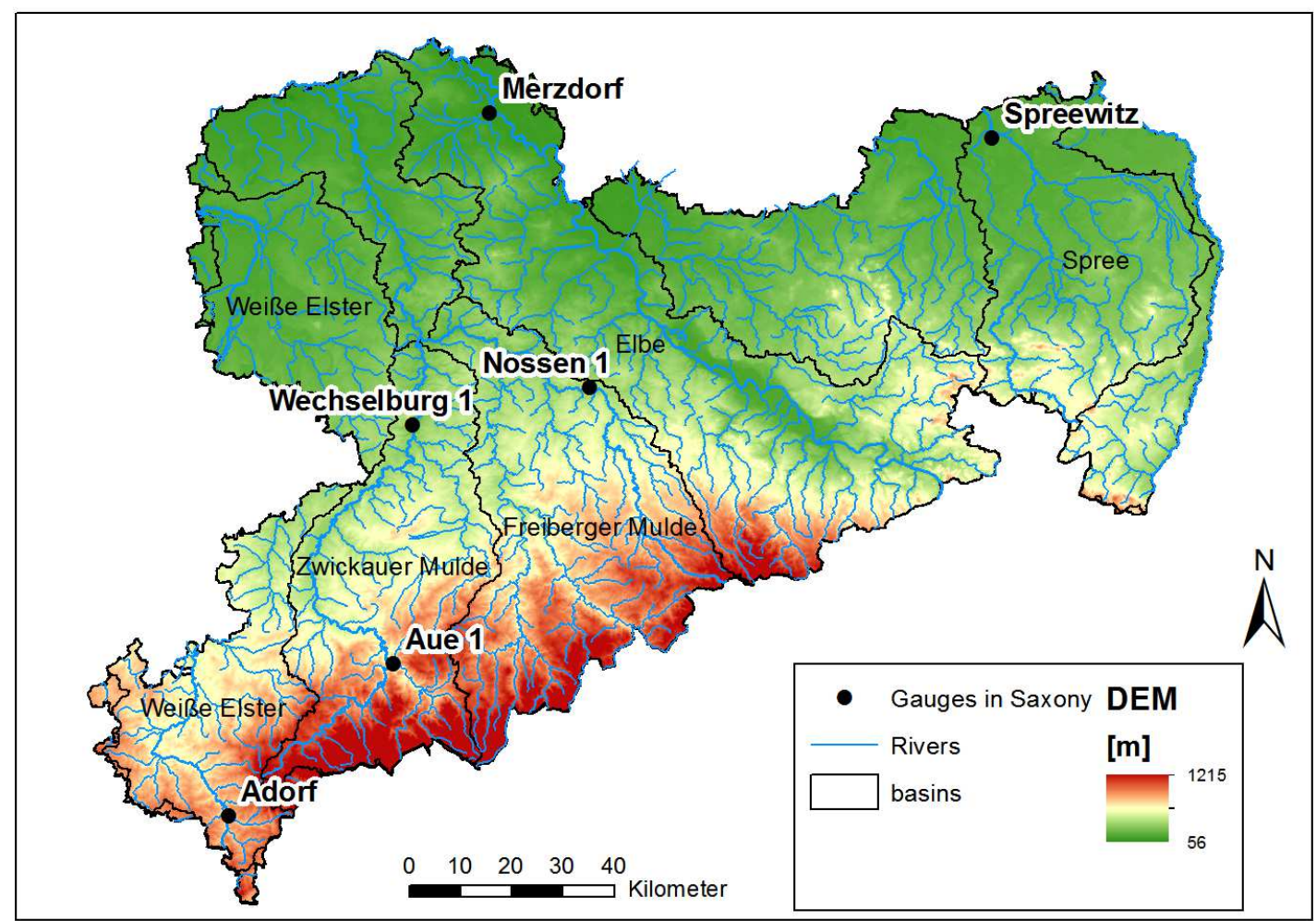

Figure 9: The gauges in the Saxony-sample

(Rhine)), but all pairs of gauges have a number of coincidences which is significantly higher than the comparison value. The coincidence in mean discharges show a general weather depending behaviour of the discharges, which is averagely the same in whole Germany. For example, there are rather wet or dry years leading to high or low mean discharges.

These results now should be compared with results of another type of extreme event, the Minimum discharges over $D$ days (NMDQ)(Table 5).

In general, there is less coincidence in the behaviour of NMDQ in comparison with the annual runoff means, independent of the considered sample. Somewhat surprising is the slight coincidence between the Cologne and Hofkirchen gauges, which was also found for the mean discharges.

If we only consider the gauges in the Mulde sample we can find high coincidences mainly in the same sub-basin, though it seems that the eastern sub-basins have more coincidences in their NMDQ values than the western. This can be explained by the dominating Atmospheric Circulation Pattern resulting North-West-cyclonic conditions, departing the Mulde river basin into two different climate parts, the eastern part of the Zwickauer Mulde und the western part with the Freiberger Mulde (see [13). Additionally, the eastern part is much more influenced by the Ore mountains. The Niederschlema gauge, which is highly influences by a reservoir only shows little coincidence to the other gauges. The low water regulation of the dam therefore prevents the gauge of low water.

We also calculated the number of coincidences for other values of $h$, namely $h=2,3,5,6,7$ and always also for the non-metrical approach. Since the results create the same picture as in the 


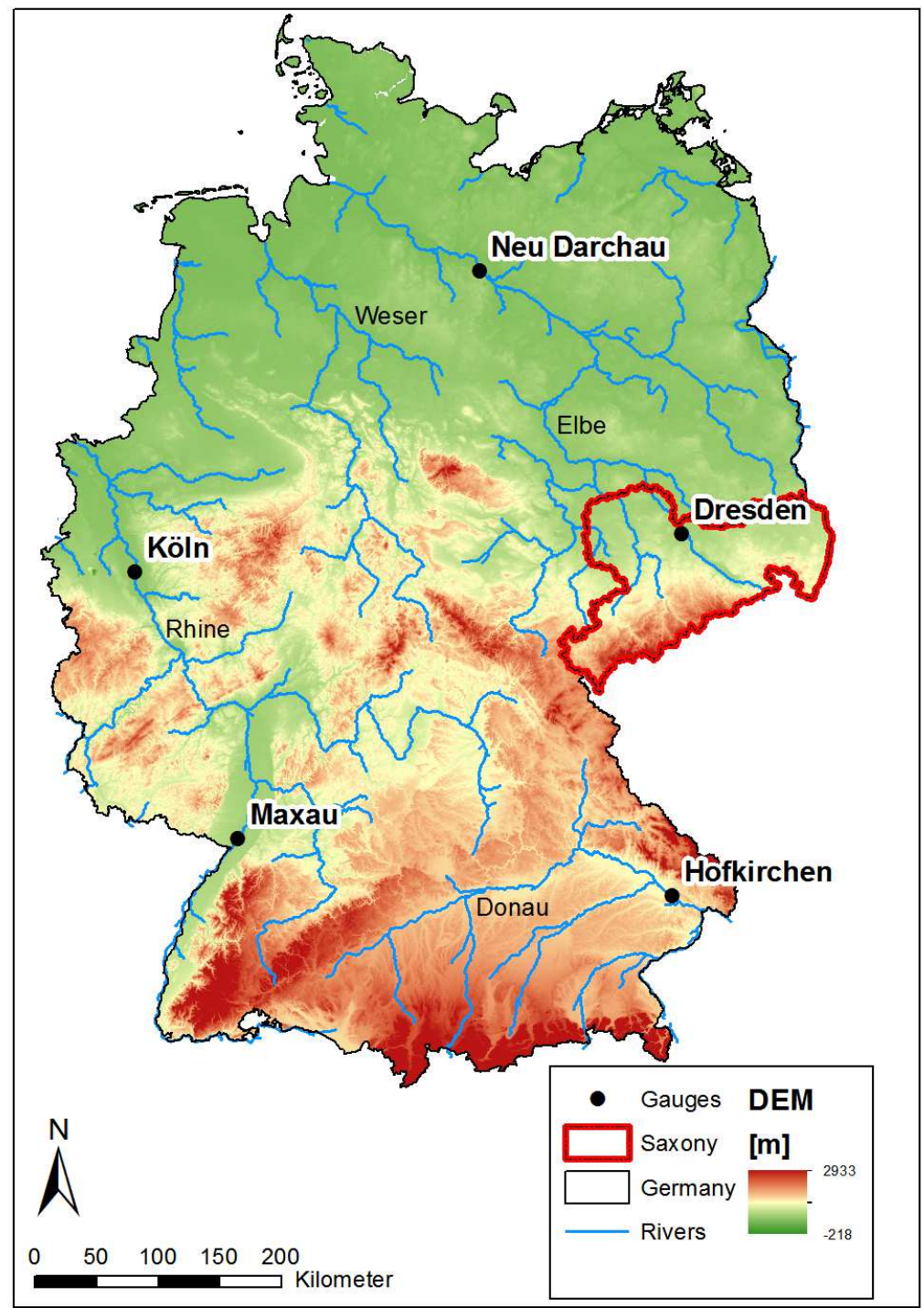

Figure 10: The gauges in the Germany-sample

case of $h=4$ and the metrical approach we spare the presentation of these results.

\section{Discussion}

The results above show the applicability of the ordinal pattern approach to hydrological time series. For different types of discharges, significant coincidences can be found between the gauges. The information obtained by this new method cannot only be used to analyse the spatial extent of weather phenomena but it also provides useful information about the similarities and differences between hydrological characteristics. In the case study described above it became possible to identify differences in the flood regime caused by urbanization and reservoirs. The relatively similar behavior of the time series of runoff means and low waters at the gauges Cologne/Rhine and Hofkirchen/Danube were surprising. This is especially the case as the gauge Maxau, that is located also at the Rhine, shows less coincidences with the series at the 


\section{Discussion}

Table 4: Number of coincidences and comparison value (in pct., respectively) for the mean discharges of the sample Mulde, Saxony and Germany calculated with the metrical ordinal pattern approach with $h=4$ and pre-processing.

\begin{tabular}{llllll}
\hline Sample & & Gauge pair & Coincidences & $v_{c, p p w}$ & Relation \\
\hline Mulde & Wechselburg & Nossen & 49.39 & 8.89 & 5.56 \\
Same basin & Berthelsdorf & Hopfgarten & 45.78 & 8.76 & 5.23 \\
& Berthelsdorf & Niederschlema & 34.51 & 8.79 & 3.93 \\
& Hopfgarten & Niederschlema & 54.91 & 8.11 & 6.77 \\
\hline Saxony & Aue 1 & Adorf & 37.01 & 7.51 & 4.93 \\
different & Wechselburg & Spreewitz & 37.79 & 7.61 & 4.97 \\
mesoscale basins & Nossen 1 & Merzdorf & 37.00 & 8.98 & 4.12 \\
\hline Germany & Cologne/Rhine & Neu-Darchau/Elbe & 27.69 & 6.83 & 4.05 \\
& Cologne/Rhine & Hofkirchen/Danube & 47.33 & 7.29 & 6.49 \\
& Cologne/Rhine & Dresden/Elbe & 24.47 & 7.33 & 3.34 \\
& Cologne/Rhine & Maxau/Rhine & 64.58 & 7.92 & 8.15 \\
& Neu-Darchau/Elbe & Hofkirchen/Danube & 31.31 & 7.44 & 4.21 \\
& Neu-Darchau/Elbe & Dresden/Elbe & 55.58 & 8.33 & 6.67 \\
& Neu-Darchau/Elbe & Maxau/Rhine & 22.59 & 7.29 & 3.10 \\
& Hofkirchen/Danube & Dresden/Elbe & 28.16 & 8.01 & 3.52 \\
& Hofkirchen/Danube & Maxau/Rhine & 39.63 & 7.70 & 5.15 \\
& Dresden/Elbe & Maxau/Rhine & 21.31 & 8.56 & 2.49 \\
\hline
\end{tabular}

Danube-gauge. A practical application of the described methodology could be in the planning hydrometric networks. To give an example, a nested group of gauges of the Zschopau sub-basin in the Mulde river basin is compared. In Figure 11 we show the coincidence of this group of gauges in relation to the quotient of their catchment area with that of the Lichtenwalde gauge at the sub-catchment outlet for both annual summer and winter maxima. As comparison also the relation of the Erlln gauge, that is located downstream, is shown.

It can be seen that for winter as well as for summer floods the coincidence decreases with increasing relation of the catchment sizes. That is, the smaller the catchments compared to the gauge at the outlet the less similar the annual maxima are. Whereas for the winter annual maxima the coincidence decreases linearly, for the summer events a logarithmical decrease can be detected. However, the very striking deviation of the Streckewalde gauge for the summer events can be explained by the dam located upstream to this gauge which is modifying the flood peaks. The Tannenberg and Borstendorf gauges show nearly no differences with the Lichtenwalde gauge for winter and summer floods. This is not the case for the other gauges. The results in this work show that there exist strong coincidences between the discharge behaviour of gauges. These can be found for extreme events (floods and low water) as well as medium discharges. The degrees of coincidences differ between the hydrological characteristics of interest depending on the main factors of influence: spatial relationships between gauges (consecutive or parallel gauges), the catchment size relation and the distance.

This study presents a possibility to measure non-linear dependence between non-stationary discharge series. The classical method of ordinal patterns is extended by a pre-processing method taking into account the high variability of discharge series. The application to several winter and summer annual maximum series of catchments located in different distances from 


\section{Discussion}

Table 5: Number of coincidences and comparison value for the NMDQ (in pct., respectively) of the sample Mulde, Saxony and Germany calculated with the metrical ordinal pattern approach with $h=4$ and pre-processing.

\begin{tabular}{llllll}
\hline Sample & & Gauge pair & Coincidences & $v_{c, w}$ & Relation \\
\hline Mulde & Wechselburg & Nossen & 24.39 & 6.15 & 3.97 \\
Same basin & Berthelsdorf & Hopfgarten & 34.51 & 6.85 & 5.04 \\
& Berthelsdorf & Niederschlema & 22.54 & 6.05 & 3.73 \\
& Hopfgarten & Niederschlema & 18.66 & 6.14 & 3.04 \\
\hline Saxony & Aue 1 & Adorf & 15.58 & 5.90 & 2.64 \\
different & Wechselburg & Spreewitz & 28.49 & 5.22 & 5.46 \\
mesoscale basins & Nossen 1 & Merzdorf & 13.75 & 6.53 & 2.11 \\
\hline Germany & Cologne/Rhine & Neu-Darchau/Elbe & 19.27 & 5.79 & 3.33 \\
& Cologne/Rhine & Hofkirchen/Danube & 37.62 & 5.59 & 6.73 \\
& Cologne/Rhine & Dresden/Elbe & 19.34 & 5.51 & 3.51 \\
& Cologne/Rhine & Maxau/Rhine & 31.47 & 6.10 & 5.16 \\
& Neu-Darchau/Elbe & Hofkirchen/Danube & 22.82 & 5.66 & 4.03 \\
& Neu-Darchau/Elbe & Dresden/Elbe & 45.42 & 6.13 & 7.41 \\
& Neu-Darchau/Elbe & Maxau/Rhine & 18.75 & 5.98 & 3.14 \\
& Hofkirchen/Danube & Dresden/Elbe & 24.03 & 5.65 & 4.25 \\
& Hofkirchen/Danube & Maxau/Rhine & 34.15 & 5.99 & 5.70 \\
& Dresden/Elbe & Maxau/Rhine & 14.77 & 5.97 & 2.98 \\
\hline
\end{tabular}

each other illustrates the possibility to detect groups behaving alike in their seasonal flood regimes. Moreover, anthropogenic impacts like the construction of a reservoir can be detected by changing coherences between time series. This information can be used not only to detect homogeneous groups but also for the planning of new gauges by using the coherence within a catchment related to a specific gauge at the estuary. If the application is extended to larger scales of catchments and different types of discharges, such as mean annual discharges or low water, still coherences between several gauges can be detected. Nevertheless, in this case no specific climate impact can explain these coherences, but there seems to be a Germany-wide coincidence of wet or dry years. For low water the coherence is the lowest, though still significant. This study underlines the usefulness of the usage of ordinal patterns in the hydrological context, since this method is not influenced by non-stationarity and is able to detect even non-linear dependence. Classical correlation methods like the Pearson correlation coefficient would fail here. Moreover, the detected coherences can be related to certain climatic or anthropogenic circumstances.

A further application could be the detection of cycles implying possible long range dependence in the data. For this, certain patterns have to be detected that indicate a change of a period of high floods to a period of lower floods or vice-versa. First results show a cycle of seven years in the winter annual maxima series of the Mulde river basin, which corresponds with many results on cycles in hydrology. 


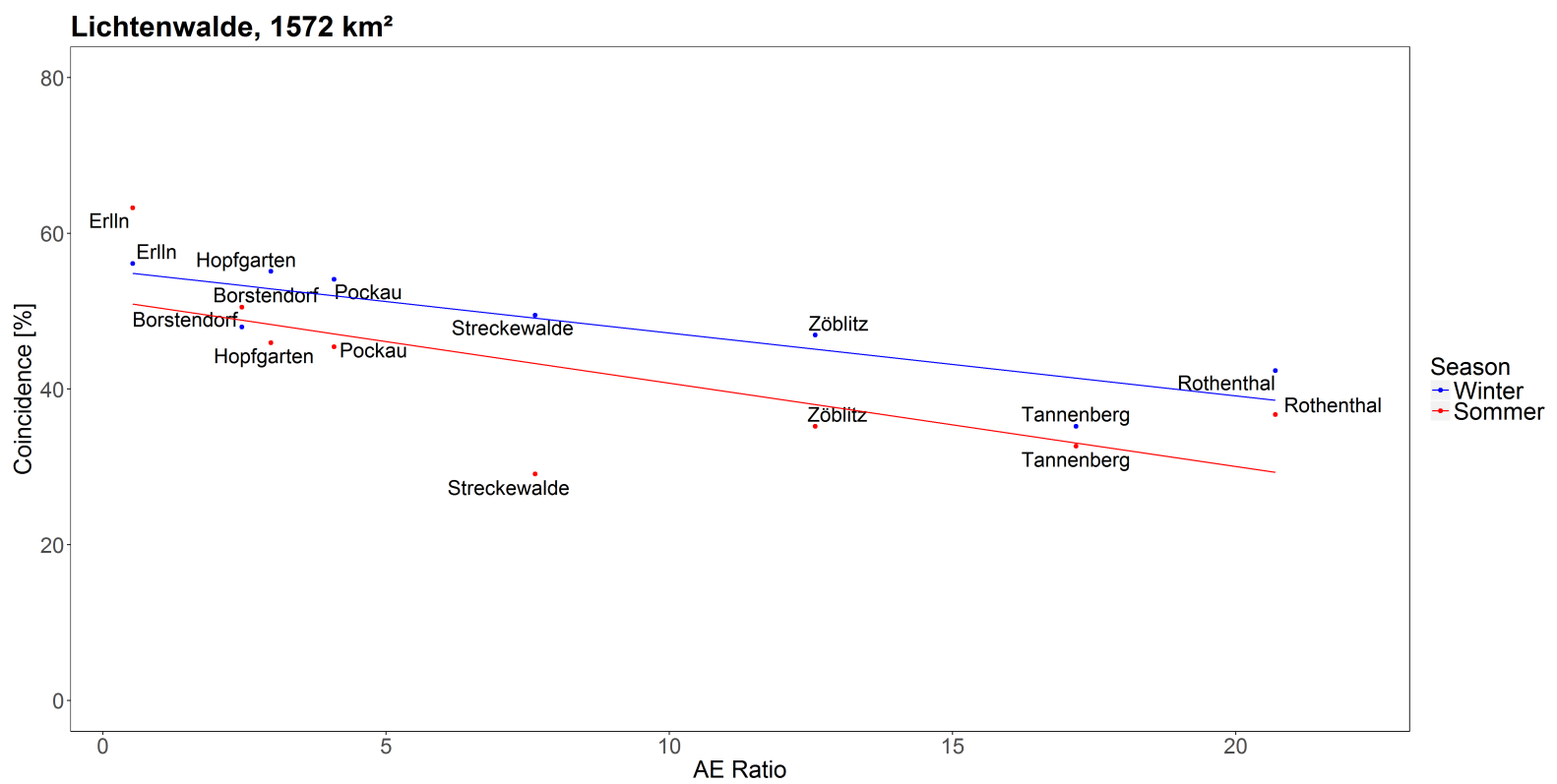

Figure 11: Relation of the catchment size quotient to the coincidence with the gauge Lichtenwalde for a sub-catchment.

\section{Acknowledgements}

Svenja Fischer was financially funded by the DFG collaborative research centre SFB 823 "Statistical modelling of nonlinear dynamic processes". Alexander Schnurr was founded by the DFGproject "Ordinal-Pattern-Dependence: Grenzwertsätze und Strukturbrüche im langzeitabhängigen Fall mit Anwendungen in Hydrologie, Medizin und Finanzmathematik" (SCHN 1231/3-1).

\section{References}

[1] Bandt, C. (2005): Ordinal time series analysis. Ecological Modelling, 182 : 229-238.

[2] Bandt, C. and B. Pompe (2002): Permutation entropy: A natural complexity measure for time series. Phys. Rev. Lett., 88174102 (4 pages).

[3] Bandt, C. and F. Shiha (2007): Order Patterns in Time Series. J. Time Ser. Anal., 28 : 646-665.

[4] Blöschl, G., Sivapalan, M., Wagener, T. Viglione, A. and Savenije, H. (2013): Runoff Prediction in Ungauged Basins. Synthesis across Processes, Places and Scales. Cambridge University Press.

[5] Clarke, R. T. (2007): Hydrological prediction in a non-stationary world. Hydr. Earth Sys. Sci. 11 (1) 408-414

[6] Fischer, S., Schumann, A. and Schulte, M. (2016): Characterisation of seasonal flood types according to timescales in mixed probability distributions. Journal of Hydrology, 539, $38-56$. 
[7] Keller, K., M. Sinn and J. Emonds (2007): Time Series from the Ordinal Viewpoint. Stochastics and Dynamics, 2 : 247-272.

[8] Keller, K. and M. Sinn (2005): Ordinal Analysis of Time Series. Physica A, 356 : 114-120.

[9] Keller, K., Unakafov A.M. and Unakafova, V.A. (2013) On the relation of KS entropy and permutation entropy. Physica D, 241 : 1477-1481.

[10] Lange, H.; Rosso, O. A.; Hauhs, M. (2013): Ordinal pattern and statistical complexity analysis of daily stream flow time series. Eur. Phys. J. Spec. Top, 222(2): 535-552.

[11] Lehmann, E.L. (1966): Some concepts of dependence. Ann. Math. Stat., 37: 1137-1153.

[12] Liu, D., Guo, S., Lian, Y., Xiong, L. and Chen, X. (2015): Climate-informed low-flow frequency analysis using nonstationary modelling. Hydrological Processes 29 (9), 10991085

[13] Petrow, Th., Merz, B., Lindenschmidt, K.-E., and Thieken, A. H. (2007): Aspects of seasonality and flood generating circulation patterns in a mountainous catchment in southeastern Germany. Hydrol. Earth Syst. Sci. 11, 1455-1468.

[14] Salas, J. and Obeysekera, J. (2014): Revisiting the Concepts of Return Period and Risk for Nonstationary Hydrologic Extreme Events. J. Hydrol. Eng. 19 (3), 554-568.

[15] Schnurr, A. (2014): An Ordinal Pattern Approach to Detect and to Model Leverage Effects and Dependence Structures Between Financial Time Series. Stat. Papers 55(4), 919-931.

[16] Schnurr, A. and Dehling, H. (2016): Testing for Structural Breaks via Ordinal Pattern Dependence. To appear in JASA; arXiv:1501.07858.

[17] Serinaldi F., Kilsby C. G. (2015): Stationarity is undead: Uncertainty dominates the distribution of extremes. Advances in Water Resources 77, 17-36

[18] Spearman C. (1904): The proof and measurement of association between two things. American Journal of Psychology 15, 72-101

[19] Sinn, M. and K. Keller (2011): Estimation of ordinal pattern probabilities in Gaussian processes with stationary increments. Comp. Stat. Data Anal., 55 : 1781-1790.

\section{Appendix}


Table 6: Coincidences (in \%) between the winter (above main diagonal) and summer annual maximum discharges (below main diagonal) of gauges in the Mulde basin with the metrical approach with $h=4$ under pre-processing. Coincidences of more than 50\% are highlighted in red, below $30 \%$ are highlighted in blue. The black boxes indicate groups of gauges belonging to the same sub-catchment.

\begin{tabular}{|c|c|c|c|c|c|c|c|c|c|c|c|c|c|c|c|c|c|c|c|c|c|c|}
\hline Gauge & River & $\mathrm{AE}\left[\mathrm{km}^{2}\right]$ & $\begin{array}{r}\text { Volfsgrund } \\
36\end{array}$ & $\begin{array}{l}\text { Berthelsdorf } \\
245\end{array}$ & $\begin{array}{l}\text { Nossen } 1 \\
586\end{array}$ & $\begin{array}{r}\text { Niederstriegis } \\
286\end{array}$ & $\begin{array}{l}\text { Erlln } \\
2980\end{array}$ & $\begin{array}{r}\text { Rothenthal } \\
76\end{array}$ & $\begin{array}{r}\text { Zblitz } \\
125\end{array}$ & $\begin{array}{r}\text { Pockau } 1 \\
385\end{array}$ & $\begin{array}{r}\text { Borstendorf } \\
640\end{array}$ & $\begin{array}{r}\text { Streckewalde } \\
206\end{array}$ & $\begin{array}{r}\text { Tannenberg } \\
92\end{array}$ & $\begin{array}{r}\text { Hopfgarten } \\
530\end{array}$ & $\begin{array}{r}\text { Lichtenwalde } \\
1572\end{array}$ & $\begin{array}{c}\text { Golzern } 1 \\
5433\end{array}$ & $\begin{array}{r}\text { Bad Dben } 1 \\
6170\end{array}$ & $\begin{array}{r}\text { Aue } 1 \\
363\end{array}$ & $\begin{array}{r}\text { Niederschlema } \\
754\end{array}$ & $\begin{array}{r}\text { Zwickau-Plbitzz } \\
1021\end{array}$ & $\begin{array}{r}\text { Gritzhain } \\
532\end{array}$ & $\begin{array}{r}\text { Wechselburg } 1 \\
2099\end{array}$ \\
\hline Wolfsgrund & \begin{tabular}{|l|} 
Chemnitzbach \\
\end{tabular} & & & 38.8 & 31.6 & 19.4 & 23.0 & 21.9 & & 40.8 & 35.7 & 34.2 & 31.6 & 31.1 & 28.6 & 23.5 & 29.6 & & 20.9 & 32.1 & & \\
\hline Berthelsdorf & Freiberger Mulde & 245 & 27.6 & & 65.3 & & & 35.2 & & 52.0 & & & & 47.5 & 54.6 & 52.0 & 56.1 & 14.8 & 34.7 & 42.9 & 42.9 & 41.8 \\
\hline Nossen 1 & Freiberger Mulde & 586 & 25.0 & 44.4 & & 52.0 & 66.3 & 37.2 & 52.0 & 57.7 & 58.7 & 51.0 & 31.1 & 56.1 & 71.9 & 66.8 & 70.9 & 18.4 & 38.8 & 50.5 & & 62.2 \\
\hline $\begin{array}{l}\text { ederstriegis } \\
\text { lln }\end{array}$ & \begin{tabular}{|l} 
Striegis \\
Freiebers
\end{tabular} & $\begin{array}{r}286 \\
2980\end{array}$ & $\begin{array}{l}15.8 \\
26.5\end{array}$ & $\begin{array}{l}27.0 \\
37.8\end{array}$ & 28.1 & & 48.5 & 51.0 & $\begin{array}{l}35.2 \\
357\end{array}$ & $\begin{array}{l}37.2 \\
47.5\end{array}$ & $\begin{array}{l}37.2 \\
48.5\end{array}$ & $\begin{array}{l}37.2 \\
38.2\end{array}$ & $\begin{array}{l}32.7 \\
34.2\end{array}$ & $\begin{array}{l}35.2 \\
41.3\end{array}$ & 47.5 & $\begin{array}{l}55.6 \\
69.9\end{array}$ & $\begin{array}{l}49.5 \\
58.7\end{array}$ & 18.4 & 40.3 & 55.6 & 48.0 & 62.2 \\
\hline thenthal & $\begin{array}{l}\text { Freiberger Mulde } \\
\text { Natzschung }\end{array}$ & $\begin{array}{l}2980 \\
76\end{array}$ & $\begin{array}{l}26.5 \\
26.5\end{array}$ & $\begin{array}{l}37.8 \\
23.5 \\
\end{array}$ & $\begin{array}{l}52.6 \\
25.0\end{array}$ & $\begin{array}{l}45.9 \\
23.5 \\
\end{array}$ & 28.6 & 37.8 & $\begin{array}{l}3.7 .7 \\
44.4\end{array}$ & $\begin{array}{l}47.5 \\
38.8\end{array}$ & $\begin{array}{l}48.5 \\
34.2\end{array}$ & $\begin{array}{l}38.8 \\
45.9\end{array}$ & $\begin{array}{l}34.2 \\
29.1\end{array}$ & $\begin{array}{l}41.3 \\
39.3\end{array}$ & $\begin{array}{l}56.1 \\
42.4\end{array}$ & 69.99 & 58.7 & $\begin{array}{l}16.3 \\
240\end{array}$ & $\begin{array}{l}38.8 \\
43.9\end{array}$ & $\begin{array}{l}49.0 \\
47.5\end{array}$ & $\begin{array}{l}48.0 \\
40.8\end{array}$ & 52.6 \\
\hline litz & Schwarze Pockau & 125 & 24.0 & 28.6 & 38.3 & 22.5 & 35.7 & 29.1 & & 50.0 & 46.9 & 50.0 & 33.7 & 54.6 & $\begin{array}{l}42.4 \\
46.9\end{array}$ & $\begin{array}{l}40.4 \\
37.2\end{array}$ & 42.4 & 20.4 & 34.7 & 43.9 & 42.4 & $\begin{array}{l}47.4 \\
43.9\end{array}$ \\
\hline ckau & Flha & 385 & 25.5 & 36.7 & 43.9 & 35.2 & 45.4 & 352 & 41.3 & & 65.8 & 50.0 & 48.5 & 55.1 & 54.1 & 49.5 & 45.9 & 21.9 & 39.3 & 46.4 & 44.9 & 46.9 \\
\hline off & & 640 & 30.1 & 31.1 & 38.3 & 31.1 & 44.9 & 36.7 & 30.6 & 49.0 & & 43.9 & 37.2 & 44.9 & 48.0 & 48.0 & 45.9 & & & 42.9 & 42.9 & 51.5 \\
\hline eckewalde & & 206 & & 23.0 & 26.0 & 24.5 & 32.7 & & 37.8 & 29.1 & 31.6 & & 35.7 & 54.6 & 49.5 & 40.3 & 44. $\mathrm{Y}-\mathrm{s}$ & & 4 & 53.1 & 42.9 & 44.9 \\
\hline Tannenbe & & & 16.3 & 24.5 & 30.6 & 24.5 & 35 & 27.0 & & & & 26.0 & & 37.2 & 35.2 & & 38 & & & & & 29.6 \\
\hline ppfgar & Zs & 530 & 23 & 21.9 & 38.8 & 29.1 & 44.9 & 29.1 & 44.9 & 41.3 & 40.8 & 36.7 & 42.9 & & 55.1 & 44.4 & 51.5 & 18.9 & 34.2 & 37.8 & 49.0 & 40.8 \\
\hline & & 1012 & 26 & 41.8 & & 39.3 & 63.3 & 36.7 & 35.2 & 70.4. & 0.0 & 29.1 & 02.1 & 45.9 & & 61.7 & 68.4 & $x^{2}+2$ & 36.7 & 48.5 & & 50.0 \\
\hline & & & 24 & 34.2 & 41.3 & & 64.3 & & 25 & & 2 & 26 & 35.7 & 42.4 & 57.7. & & 67.9 & 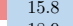 & No & 52.6 & 51.0 & 59.2 \\
\hline$d$ Dben 1 & Vereinigte Mulde & $\begin{array}{l}6170 \\
636\end{array}$ & 25.0 & 25.5 & 34.2 & 40.3 & 53.6 & 35.7 & 24.0 & 33.2 & 40.3 & 25.5 & 32.1 & 42.4 & 48.0 & 67.9 & & 18.9 & 40.8 & 52.0 & 60.2 & 57.1 \\
\hline $\begin{array}{l}\text { ile } 1 \\
\text { ederschle }\end{array}$ & | Schwis & $\begin{array}{l}363 \\
754\end{array}$ & $\begin{array}{l}19.9 \\
17.4\end{array}$ & $\begin{array}{l}30.1 \\
29.1\end{array}$ & 24.5 & $\begin{array}{l}21.99 \\
29.6\end{array}$ & $\begin{array}{l}32.7 \\
25.0\end{array}$ & $\begin{array}{l}24.0 \\
23.0\end{array}$ & $\begin{array}{l}21.4 \\
18.9\end{array}$ & $\begin{array}{l}31.1 \\
25.0\end{array}$ & $\begin{array}{l}24.0 \\
25.0\end{array}$ & $\begin{array}{l}25.0 \\
16.8\end{array}$ & $\begin{array}{l}40.3 \\
321\end{array}$ & . & 29.1 & 33.7 & ${ }_{43.3}^{40.3}$ & & 23.5 & 25.5 & 18.4 & 17.99 \\
\hline 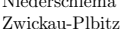 & Zwickauer Mulde & $\begin{array}{c}1021 \\
1021\end{array}$ & 19.4 & 31.6 & $\begin{array}{l}24.9 \\
21.9\end{array}$ & $\begin{array}{l}29.0 \\
27.0\end{array}$ & $\begin{array}{l}20 \\
26\end{array}$ & 30.1 & $\begin{array}{l}18.9 \\
22.5\end{array}$ & 30.6 & 29.6 & $\begin{array}{l}10.8 \\
20.4\end{array}$ & $\begin{array}{l}32.1 \\
33.7\end{array}$ & 20 & $\begin{array}{l}29.0 \\
28.6\end{array}$ & $\begin{array}{l}33.1 \\
33.2\end{array}$ & $\begin{array}{l}43.4 \\
45.4\end{array}$ & $\begin{array}{l}01.5 \\
49.5\end{array}$ & 67.9 & & 39.8 & 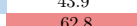 \\
\hline & & 532 & 150 & , & 14.8 & 20.4 & 21.4 & 107 & 14.3 & 18.9 & 16.3 & 14.3 & 235 & 18.4 & 20.4 & 70 & 10 & & 4 & 3.9 & & 55.6 \\
\hline Wechselburg 1 & wickauer Mulde & 2099 & 20.9 & 31.1 & 27.6 & 51.5 & 41.3 & 19.9 & 23.5 & 37.2 & 31.1 & 18.4 & 31.1 & 35.7. & 35.7 & 55.6 & 49.0 & 29.6 & 40.8 & 45.9 & 29.1 & \\
\hline
\end{tabular}




